\title{
DAMPAK KOMUNIKASI PEMASARAN TERHADAP KEPUASAN DAN LOYALITAS PELANGGAN PADA PT. CAHAYA ALAM SEJATI
}

\author{
Fifi Dwi Pratiwi dan Zuwina Miraza \\ fifidwi.pratiwi@yahoo.com; zuwinamiraza@gmail.com \\ Fakultas Ekonomi Bisnis Universitas Harapan Medan
}

\begin{abstract}
Abstrak
This research aims to determine the Effect of: (1) Marketing Communication on Costumer Loyalty of PT. Cahaya Alam Sejati, (2) Marketing Communication on Costomer Satisfaction of PT. Cahaya Alam Sejati, (3) Marketing Communication on Costumer Loyalty of PT. Cahaya Alam Sejati by Costumer Satisfaction as a mediating variable. This is a descriptive quantitative research. The research population is service costumer at PT. Cahaya Alam Sejati. The research sample is convenience sampling of 100 person. Primary data obtained from questionnaires, analysis techniques data used in this research is multiple regression analysis along the path analysis. Result of research indicate that: (1) Marketing Communication affect positively and significantly on Costomer Satisfaction of PT. Cahaya Alam Sejati, (2) Marketing Communication affect positively and significantly on Costumer Loyalty of PT. Cahaya Alam Sejati, (3) Costumer Satisfaction mediated the effect of Marketing Communikation on Costumer Loyality of PT. Cahaya Alam Sejati.
\end{abstract}

\section{Keywords: Marketing Communication, Costomer Satisfaction, Costomer Loyality}

\section{PENDAHULUAN}

\section{Latar Belakang Masalah}

Berkembangnya dinamika usaha mengakibatkan timbulnya persaingan yang semakin kompleks yang dihadapi oleh perusahaan, baik secara langsung maupun tidak langsung. Untuk itu suatu perusahaan diharuskan memiliki daya saing yang lebih tinggi dibandingkan dengan perusahaan-perusahaan lain sejenisnya dan mampu mempertahankan posisinya.

Pertumbuhan industri di Indonesia terutama di Medan-Sumatera Utara, membuat para pengusaha berlomba-lomba merebut pangsa pasar terutama di industri kotak karton. Industri kotak karton adalah industri yang sangat penting bagi perusahaan lain, sebagai alat untuk memindahkan produknya agar tidak rusak sampai ke tangan konsumen, melindungi isi kemasaran agar tidak terbentur, mempermudah pengiriman produk dalam container dan bisa menjadi alat promosi/iklan. Oleh karena itu, kemasan kotak karton menjadi suatu bagian yang tidak dapat dipisahkan bagi perusahan lain yang membutuhkannya, dan bisa menjadi strategi pemasaran produk oleh perusahaan tersebut.

Untuk membantu perkembangan perusahaan perlu dijalankan komunikasi yang baik dengan pelanggan yang merupakan bagian dari bauran pemasaran. Dengan adanya komunikasi yang baik bisa membantu mempertahankan pelanggan dan menarik pelanggan yang baru. Perusahaan biasanya melakukan komunikasi pemasaran yang sesuai dengan karakter pelanggan sasarannya, bisa melalui konsep komunikasi pemasaran seperti, periklanan, promosi penjualan, pemasaran langsung, pemasaran personal, dan 
relasi publik. Dengan tercapainya komunikasi pemasaran yang baik, konsumen akan merasa kebutuhan dan keinginannya terpenuhi. Selanjutnya, konsumen akan loyal pada perusahaan.

PT. Cahaya Alam Sejati adalah perusahaan yang bergerak di bidang Industri kotak karton, yang berusaha untuk mengerti tentang kebutuhan akan kemasan kotak karton bagi customer (pelanggan). Sehingga PT Cahaya Alam Sejati selalu berkomitmen untuk, menjaga kualitas produk kemasan, on time delivery, dan Selalu siap memberikan solusi masalah kemasan. Memberikan pelayanan yang paling baik dengan motto "Kepuasan Pelanggan adalah Harga dari Produk".

Adapun perusahaan yang bergerak di bidang industri yang sama seperti, PT. Pembungkus Internasional, PT. Sumatera Hakarindo, dan PT. Kotak Kreasi Megah. Sehingga membuat PT. Cahaya Alam Sejati terus berinovasi dan selalu memberikan yang terbaik kepada pelanggannya. Agar perusahaan yang sudah bekerjasama dengan PT. Cahaya Alam Sejati terus loyal dan tidak berpaling keperusahaan yang lain.

PT. Cahaya Alam Sejati telah berpengalaman dalam hal penyediaan kemasan kotak karton. Saat ini, PT. Cahaya Alam Sejati telah berkerjasama dengan beberapa Perusahaan Besar berskala Nasional di Pulau Sumatera, beberapa diantaranya, PT. Indofood Sukses Mandiri, Tbk sebagai kemasan karton indomie, PT. Siantar Top, Tbk sebagai kemasan karton snack (makanan ringan), PT. Garuda Food sebagai kemasan karton minuman/ snack (makanan ringan), PT. Pasific Medan Industri sebagai kemasan karton minyak, PT. Oleochem \& Soap Industri sebagai kemasan karton sabun, PT. Musim Mas sebagai kemasan karton minyak, PT. Wilmar Goup sebagai kemasan karton minyak.

Dalam kiprahnya sebagai salah satu perusahaan industri kotak karton, PT. Cahaya Alam Sejati menghadapi banyak persaingan. Untuk menjaga loyalitas pelanggan, dan tetap memenuhi kebutuhan dan keinginan pelanggan, PT. Cahaya Alam Sejati hendaknya memerhatikan dari berbagai dimensi. Dimyati (2015) menemukan bahwa "komunikasi pemasaran berpengaruh positif secara signifikan terhadap loyalitas pelanggan melalui kepuasan pelanggan sebagai variabel mediasi dan kepuasan pelanggan berpengaruh positif secara signifikan terhadap loyalitas pelanggan". Penelitian Purwanto dan Widodo (2016) membuktikan bahwa terdapat pengaruh langsung secara positif antara komunikasi pemasaran dan kualitas produk terhadap loyalitas. Hasil penelitian juga membuktikan bahwa kepercayaan merupakan intervening positip antara komunikasi pemasaran dan kualitas produk terhadap loyalitas konsumen". Penelitian yang sama juga dengan path analysis dibuktikan oleh Pristiyono (2017) membuktikan bahwa variabel kepuasan nasabah secara langsung berpengaruh terhadap variabel loyalitas nasabah.

Penelitian-penelitian di atas membuktikan bahwa PT. Cahaya Alam Sejati memerlukan komunikasi pemasaran yang baik untuk menyampaikan pesan kepada publik terutama pelanggan sebagai sasaran mengenai keberadaan produk di pasar. Komunikasi pemasaran memegang peranan yang sangat penting bagi pemasar. Tanpa komunikasi, konsumen ataupun pelanggan secara keseluruhan tidak akan mengetahui informasi dari perusahaan tentang produknya.

Kepuasan pelanggan pada saat ini, sangat diperlukan di dalam suatu bisnis karena dapat mendatangkan banyak keuntungan dalam jangka waktu yang panjang. Oleh karena itu perusahaan harus menerapkan strategi yang tepat dengan tujuan mempertahankan para pelanggannya untuk melakukan pembelian kembali (repurchase).

Tjiptono dan Chandra (2016) mengatakan bahwa "loyalitas pelanggan kerapkali dikaitkan dengan perilaku pembelian ulang”. Pembelian ulang bisa pula merupakan hasil 
upaya promosi terus-menerus dalam rangka memikat dan membujuk pelanggan untuk membeli kembali produk yang sama.

\section{Rumusan Masalah}

Untuk mengetahui pengaruh pada identifikasi masalah yang akan diteliti dalam penelitian ini, maka perumusan masalah penelitian adalah:

1. Apakah Komunikasi Pemasaran berpengaruh positif signifikan terhadap Loyalitas Pelanggan pada PT. Cahaya Alam Sejati?

2. Apakah Komunikasi Pemasaran berpengaruh positif signifikan terhadap Kepuasan Pelanggan pada PT. Cahaya Alam Sejati?

3. Apakah Kepuasan Pelanggan memediasi Komunikasi Pemasaran terhadap Loyalitas Pelanggan pada PT. Cahaya Alam Sejati?

\section{KAJIAN TEORITIS \\ Komunikasi Pemasaran}

Komunikasi pemasaran merupa-kan usaha untuk menyampaikan pesan kepada publik terutama konsumen sebagai sasaran mengenai keberadaan produk di pasar. Komunikasi pemasaran memegang peranan yang sangat penting bagi pemasar. Tanpa komunikasi, konsumen ataupun pelanggan secara keseluruhan tidak akan mengetahui keberadaan produk di pasar.

\section{Kepuasan Pelanggan}

Menurut Tjiptono dan Chandra (2012) "peningkatan kepuasan pe-langgan berpotensi mengarah pada pertumbuhan penjualan jangka panjang maupun jangka pedek, serta pangsa pasar sebagai hasil dari pembelian ulang”. Sementara itu, ketidakpuasan pelanggan sesungguhnya bisa membawa perusahaan mengidentifikasi aspek-aspek yang menjadi kelemahan produk/jasa yang tidak memenuhi standar konsumen dan pemerintah.

Kotler dan Keller (2009) mendefinisikan "kepuasan sebagai sikap terhadap hasil transaksi dan dari kepuasan yang diperkirakan akan mempengaruhi perilaku lanjutan atau kesetiaan pelanggan". Upaya perusahaan dalam memberikan yang terbaik bagi pelanggannya agar apa yang diharapkan oleh mereka sesuai kenyataan sehingga mereka puas dan akan membentuk pengalaman konsumsi dalam hal yang positif.

\section{Loyalitas Pelanggan}

Kotler dan Keller (2009) mendefinisikan "loyalitas pelanggan sebagai komitmen untuk membeli kembali produk atau jasa di masa yang akan datang meskipun dipengaruhi oleh situasi dan keadaan pasar yang dapat menyebabkan perubahan perilaku”. Untuk mendapatkan loyalitas pelanggan, perusahaan perlu melakukan strategi pemasaran yang tepat agar dapat mempengaruhi loyalitas pelanggannya. Loyalitas pelanggan kerapkali dikaitkan dengan perilaku pembelian ulang. Pembelian ulang bisa merupakan hasil dominasi pasar oleh perusahaan yang berhasil membuat produknya menjadi satu-satunya alternatif yang tersedia. Selain itu, pembelian ulang bisa pula merupakan hasil upaya promosi terus-menerus dalam rangka memikat dan membujuk pelanggan untuk membeli kembali merek yang sama. Pelanggan yang loyal pada merek tertentu cenderung 'terikat' pada merek tersebut dan bakal membeli produk yang sama lagi sekalipun tersedia banyak alternatif lain. 


\section{Kerangka Konseptual}

Berdasarkan pemikiran diatas maka kerangka konseptual yang mendasari penelitian adalah sebagai berikut :

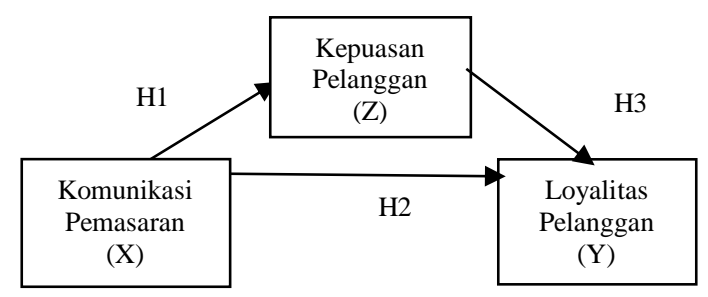

\section{Gambar 1. Kerangka Konseptual}

\section{Hipotesis Penelitian}

Berdasarkan penelitian terdahulu dan kerangka konseptual, maka hipotesis dapat dirumuskan, sebagai berikut:

H1 : Komunikasi Pemasaran ber-pengaruh positif signifikan terhadap Loyalitas Pelanggan pada PT. Cahaya Alam Sejati.

$\mathrm{H} 2$ : Komunikasi Pemasaran ber-pengaruh positif signifikan terhadap Kepuasan Pelanggan pada PT. Cahaya Alam Sejati.

H3 : Kepuasan Pelanggan memediasi Komunikasi Pemasaran terhadap Loyalitas Pelanggan pada PT. Cahaya Alam Sejati.

\section{METODE PENELITIAN}

Penelitian ini dilakukan di Jl. Pulau Pinang, Kawasan Industri Medan II MabarSaentis, Medan - Sumatera Utara. Populasi dalam penelitian ini adalah pelanggan/perusahaan yang pernah membeli kotak karton pada PT. Cahaya Alam Sejati, jumlah populasi sebanyak 200 pelanggan/perusahaan. Data yang digunakan adalah data primer ayang diperoleh dari responden secara langsung di lokasi penelitian melalui kuesioner dan wawancara kepada responden yang dilakukan pada penelitian awal sampai selesai.

Teknik pengumpilan data yang digunakan adalah kuesioner, dengan skala likert 1 sampai dengan 5. Untuk membuktikan kebenaran hipotesis digunakan uji distribusi $\mathrm{F}$. Apabila perhitungan F-tabel signifikan pada 0,05 $(\alpha<0,05)$ maka Ho ditolak sehingga dapat dikatakan bahwa variabel bebas dari regresi dapat menerangkan variabel terikat secara serentak. Sebaliknya, jika $\alpha>0,05$ maka Ho diterima, sehinga dapat dikatakan bahwa variabel bebas tidak menjelaskan variabel terikat. Selain secara simultan, uji kesesuaian juga dilakukan serara parsial. Uji signifikan parsial atau individual adalah uji yang digunakan untuk menguji apakah suatu variabel independen berpengaruh atau tidak terhadap variabel dependen. Apabila t-tabel signifikan pada $0,05 \quad(\alpha<0,05)$, maka Ho ditolak, dengan demikian variabel bebas menerangkan variabel terikat. Sebaliknya apabila $\alpha>0,05$ maka Ho diterima sehingga dapat dikatakan variabel bebas tidak dapat menjelaskan variable berikutnya. Dengan kata lain, tidak ada pengaruh diantara variabel yang diuji. 


\section{Sobel Test}

Untuk menguji pengaruh variabel intervening digunakan metode analisis jalur (Path Analysis). Analisis jalur merupakan perluasan dari analisis linear berganda, atau analisis jalur adalah penggunaan analisis regresi untuk menaksir hubungan kausalitas antar variabel (model casual) yang telah ditetapkan sebelumnya berdasarkan teori (Ghozali, 2013). Menurut Ghozali (2013) "untuk menghitung persamaan skruktural pada Path Analysis digunakan koefisien jalur. Koefisien jalur adalah standardized koefisien regresi, yaitu persamaan regresi yang menunjukkan hubungan yang dihipotesiskan". Maka pembuktian hipotesis ini menggunakan persamaan, yaitu :

$$
\begin{aligned}
& \mathrm{Z}=\alpha+b 2 \mathrm{X} \\
& \mathrm{Y}=\alpha+b 2 \mathrm{X}+b 3 \mathrm{Z}
\end{aligned}
$$

Standardize koefisien untuk $\mathrm{Z}$ pada hipotesis (2) akan memberikan nilai pada $b 2$. Sedangkan pada hipotesis (3) untuk $\mathrm{X}$ dan $\mathrm{Z}$ akan memberikan nilai $b 2$ dan $b 3$. Pengaruh mediasi yang ditunjukkan oleh perkalian (b2 x b3) diuji dengan sobel test:

Hitung standar error dari koefisien indirect effect is (Sp2p3)

$$
\mathrm{Sp} 2 \mathrm{p} 3=\sqrt{\mathrm{p}^{2} \mathrm{Sp}^{2}+\mathrm{p}^{2} \mathrm{Sp}^{2}+\mathrm{Sp}^{2} \mathrm{sp}^{2}}
$$

Berdasarkan hasil Sp2p3 ini kita dapat menghitung nilai t statistik pengaruh mediasi dengan rumus sebagai berikut :

$$
t=\frac{p 2 p 3}{S p 2 p 3}
$$

Jika nilai t hitung lebih besar dari t tabel dengan tingkat signifikansi 0,05, maka dapat disimpulkan bahwa koefisien signifikan yang berarti ada pengaruh mediasi.

\section{HASIL PENELITIAN DAN PEMBAHASAN}

\section{Hasil Penelitian \\ Uji Validitas}

Berikut ini adalah hasil dari 100 sampel dengan 18 item pernyataan, yang dibagi menjadi 3 variabel utama yaitu, $\mathrm{X}=$ komunikasi pemasaran, $\mathrm{Y}=$ loyalitas pelanggan dan $\mathrm{Z}=$ kepuasan pelanggan. Dasar pertimbangan untuk mengetahui valid tidaknya kuesioner adalah dengan melihat $r$ hitung. Item kuesioner dikatakan valid jika $r$ hitung lebih besar dari $r$ tabel. Nilai $r$ tabel untuk penelitian ini adalah $r$ tabel dengan $d f=n-2$, dalam hal ini $\mathrm{n}$ adalah jumlah sampel. Maka dapat dihitung $100-2=98$, dengan $\mathrm{df}=98$ dan alpha $=0,05$ didapat $r$ tabel $=0,197$. Hasil validitas dapat dilihat pada tabel berikut:

\section{Tabel 1. Hasil Uji Validitas}

\begin{tabular}{|c|c|c|c|c|}
\hline Variabel & $\begin{array}{c}\text { Item } \\
\text { Pernyataan }\end{array}$ & $\begin{array}{c}\mathrm{r} \\
\text { hitung }\end{array}$ & $\begin{array}{c}\mathrm{r} \\
\text { table }\end{array}$ & Ket \\
\hline \multirow{3}{*}{$\begin{array}{c}\text { Komunikasi } \\
\text { Pemasaran } \\
(\mathrm{X})\end{array}$} & $\mathrm{Q} 1$ &, 793 & 0,197 & Valid \\
\cline { 2 - 5 } & $\mathrm{Q} 2$ &, 657 & 0,197 & Valid \\
\cline { 2 - 5 } & $\mathrm{Q} 3$ &, 832 & 0,197 & Valid \\
\cline { 2 - 5 } & $\mathrm{Q} 4$ &, 701 & 0,197 & Valid \\
\hline & $\mathrm{Q} 5$ &, 833 & 0,197 & Valid \\
\hline & $\mathrm{Q} 1$ &, 784 & 0,197 & Valid \\
\hline
\end{tabular}


Sumber: Data Diolah, 2018

\begin{tabular}{|c|c|c|c|c|}
\hline \multirow{4}{*}{$\begin{array}{c}\text { Loyalitas } \\
\text { Pelanggan } \\
\text { (Y) }\end{array}$} & Q2 &, 776 & 0,197 & Valid \\
\cline { 2 - 5 } & Q3 &, 771 & 0,197 & Valid \\
\cline { 2 - 5 } & Q4 &, 795 & 0,197 & Valid \\
\cline { 2 - 5 } & Q5 &, 828 & 0,197 & Valid \\
\hline \multirow{4}{*}{$\begin{array}{c}\text { Kepuasan } \\
\text { Pelanggan } \\
\text { (Z) }\end{array}$} & Q1 &, 775 & 0,197 & Valid \\
\cline { 2 - 5 } & Q2 &, 683 & 0,197 & Valid \\
\cline { 2 - 5 } & Q3 &, 713 & 0,197 & Valid \\
\cline { 2 - 5 } & Q5 &, 661 & 0,197 & Valid \\
\cline { 2 - 5 } & Q6 &, 675 & 0,197 & Valid \\
\cline { 2 - 5 } & Q7 &, 725 & 0,197 & Valid \\
\hline
\end{tabular}

Dari hasil uji validitas yang dilakukan dapat diketahui dari 18 pernyataan, semua pernyataan dinyatakan valid.

\section{Uji Reliabilitas}

Untuk mengukur reliabilitas peneliti menggunakan uji statistik Cronbach Alpha ( $\alpha$ ) dengan alat bantu SPSS. Suatu konstruk atau variabel dikatakan reliabel jika memberikan nilai Cronbach Alpha > 0,7 (Nunnaly dalam Ghozali, 2013). Hasil reliabilitas dapat dilihat pada tabel berikut 2 .

Mengacu pada tabel dapat dilihat bahwa nilai Cronbach Alpha sebesar X= $0.823>0.7, \mathrm{Y}=0.877>0.7, \mathrm{Z}=0.812>0.7$ maka semua variabel tersebut dinyatakan reliabel dan dapat digunakan untuk penelitian.

Tabel 2. Hasil Uji Reliabilitas

\begin{tabular}{|c|c|c|c|}
\hline Variabel & $\begin{array}{c}\text { Cronbach } \\
\text { Alpha }\end{array}$ & $\begin{array}{c}\text { Keten- } \\
\text { tuan }\end{array}$ & Ket \\
\hline $\begin{array}{c}\text { Komunikasi } \\
\text { Pemasaran (X) }\end{array}$ &, 823 & 0,7 & Reliabel \\
\hline $\begin{array}{c}\text { Loyalitas } \\
\text { Pelanggan (Y) }\end{array}$ &, 877 & 0,7 & Reliabel \\
\hline $\begin{array}{c}\text { Kepuasan } \\
\text { Pelanggan (Z) }\end{array}$ &, 812 & 0,7 & Reliabel \\
\hline
\end{tabular}

Sumber: Data Diolah, 2018

\section{Uji Hipotesis}

\section{Pengaruh Komunikasi Pemasaran Terhadap Loyalitas Pelanggan}

Hipotesis Pertama menyatakan Bahwa Komunikasi Pemasaran berpengaruh positif signifikan terhadap Loyalitas Pelanggan. Untuk membuktikannya dilakukan uji regresi sederhana, berikut merupakan hasil uji t dari Hipotesis pertama.

\section{Tabel 3. Hasil Uji Regresi Hipotesis 1}

\begin{tabular}{|l|l|c|c|c|c|c|}
\hline \multicolumn{7}{|c|}{ Coefficients $^{\mathbf{a}}$} \\
\hline \multirow{2}{*}{ Model } & \multicolumn{2}{|c|}{$\begin{array}{c}\text { Unstandardized } \\
\text { Coefficients }\end{array}$} & $\begin{array}{l}\text { Standardized } \\
\text { Coefficients }\end{array}$ & & \\
\cline { 2 - 5 } & $\mathrm{B}$ & Std. Error & Beta & $\mathrm{T}$ & Sig. \\
\hline \multirow{2}{*}{1} & $($ Constant $)$ & 3.356 & 1.126 & & 2.979 & .004 \\
\cline { 2 - 5 } & Komp & 1.003 & .062 & .855 & 16.304 & .000 \\
\hline
\end{tabular}

Dependent Variable: loyal

Sumber: Data Diolah, 2018 
Tabel di atas memperlihatkan hasil pengujian pengaruh variabel Komunikasi Pemasaran terhadap Loyalitas Pelanggan. Dari tabel tersebut diketahui bahwa nilai signifikansinya adalah 0,000 sehingga Komunikasi Pemasaran memiliki pengaruh signifikan terhadap Loyalitas Pelanggan.

\section{Pengaruh Komunikasi Pemasaran Terhadap Kepuasan Pelanggan}

Hipotesis kedua menyatakan Bahwa Komunikasi Pemasaran berpengaruh positif signifikan terhadap Kepuasan Pelanggan. Untuk membuktikannya dilakukan uji regresi sederhana, berikut merupakan hasil uji t dari Hipotesis kedua.

\section{Tabel 4. Hasil Uji Regresi Hipotesis 2}

a. Dependent Variable: kep

\begin{tabular}{|c|c|c|c|c|c|c|}
\hline \multicolumn{7}{|c|}{ Coefficients $^{\mathrm{a}}$} \\
\hline \multirow{2}{*}{\multicolumn{2}{|c|}{ Model }} & \multicolumn{2}{|c|}{$\begin{array}{l}\text { Unstandardize } \\
\text { d Coefficients }\end{array}$} & \multirow{2}{*}{$\begin{array}{c}\text { Standardized } \\
\text { Coefficients } \\
\text { Beta }\end{array}$} & \multirow[b]{2}{*}{$\mathrm{T}$} & \multirow[b]{2}{*}{ Sig. } \\
\hline & & B & $\begin{array}{c}\text { Std. } \\
\text { Error }\end{array}$ & & & \\
\hline 1 & (Constant) & 7.529 & 1.442 & & 5.221 & .000 \\
\hline & Komp & .927 & .079 & .765 & 11.773 & .000 \\
\hline
\end{tabular}

Sumber: Data Diolah, 2018

Dari tabel tersebut diketahui bahwa nilai signifikansinya adalah 0,000 sehingga Komunikasi Pemasaran memiliki pengaruh signifikan terhadap Kepuasan Pelanggan. Hasil persamaan Regresi yaitu Z =7,529 + 0,927X dan Model Hipotesis 2 adalah sebagai berikut:

\begin{tabular}{|c|c|c|}
\hline $\begin{array}{c}\text { Komunikasi } \\
\text { Pemasaran }(\mathrm{X})\end{array}$ & 0,927 \\
\cline { 2 - 2 } & & $\begin{array}{c}\text { Loyalitas } \\
\text { Pelanggan }(\mathrm{Y})\end{array}$ \\
\hline
\end{tabular}

\section{Gambar 2. Model Hipotesis 2}

Kepuasan Pelanggan memediasi pengaruh Komunikasi Pemasaran terhadap Loyalitas Pelanggan.

Tabel 5. Tabel Anova Hasil Uji Regresi Hipotesis 3

\begin{tabular}{|l|c|c|c|c|c|c|}
\hline \multicolumn{7}{|c|}{ ANOVA $^{\mathbf{a}}$} \\
\hline \multirow{2}{*}{ Model } & $\begin{array}{c}\text { Sum of } \\
\text { Squares }\end{array}$ & df & $\begin{array}{c}\text { Mean } \\
\text { Square }\end{array}$ & F & Sig. \\
\hline \multirow{2}{*}{1} & Regression & 1124,170 & 2 & 562,085 & 168,102 &, $000^{\mathrm{b}}$ \\
\cline { 2 - 8 } & Residual & 324,340 & 97 & 3,344 & & \\
\cline { 2 - 8 } & Total & 1448,510 & 99 & & & \\
\hline
\end{tabular}

a. Dependent Variable: loyal

b. Predictors: (Constant), kep, komp

Sumber: Data Diolah, 2018

Persamaan ketiga menyebutkan bahwa Kepuasan pelanggan memediasi hubungan Komunikasi Pemasaran terhadap Loyalitas pelanggan. Untuk membuktikannya dilakukan regresi linier berganda dengan pendekatan analisis jalur. Tabel di bawah 
memperlihatkan hasil pengujian hipotesis ketiga secara simultan (uji F) dan hasil pengujian hipotesis ketiga secara persial (uji t).

\section{Tabel 4. Tabel t Hasil Uji Regresi Hipotesis 4}

\begin{tabular}{|c|c|c|c|c|c|c|}
\hline \multicolumn{7}{|c|}{ Coefficients $^{\mathrm{a}}$} \\
\hline \multirow{2}{*}{\multicolumn{2}{|c|}{ Model }} & \multicolumn{2}{|c|}{$\begin{array}{c}\text { Unstandardized } \\
\text { Coefficients }\end{array}$} & \multirow{2}{*}{$\begin{array}{l}\text { Stand } \\
\text { Coeff } \\
\text { Beta }\end{array}$} & \multirow[b]{2}{*}{$\mathrm{t}$} & \multirow[b]{2}{*}{ Sig. } \\
\hline & & B & $\begin{array}{l}\text { Std. } \\
\text { Error }\end{array}$ & & & \\
\hline \multirow[t]{3}{*}{1} & (Constant) & .940 & 1.167 & & .805 & .423 \\
\hline & Komp & .705 & .088 & .601 & 8.053 & .000 \\
\hline & Kep & .321 & .072 & .331 & 4.437 & .000 \\
\hline
\end{tabular}

a. Dependent Variable: loyal

b. Predictors: (Constant), kep, komp

Sumber: Data Diolah, 2018

Hasil pengujian mengindikasikan pengaruh variabel komunikasi pemasaran terhadap loyalitas pelanggan dengan mediasi kepuasan pelanggan. Pada tabel di atas terlihat secara simultan (tabel F), komunikasi pemasaran dan kepuasan pelanggan berpengaruh signifikan terhadap loyalitas pelanggan, dibuktikan dengan nilai signifikansi anova 0,000. Secara parsial (tabel t), komunikasi pemasaran dan kepuasan pelanggan berpengaruh signifikan terhadap loyalitas pelanggan, dibuktikan dengan signifikansi masing-masing sebesar 0,000 dan 0,000 yang lebih kecil dari 0,05.

\section{Sobel Test}

Hasil output SPSS memberikan nilai standardized beta pada hipotesis (2) sebesar 0,927 dan signifikan pada 0,000 yang berarti Komunikasi Pemasaran (X) mempengaruhi Kepuasan Pelanggan (Z). Nilai koefisien unstandardized beta 0,927 merupakan nilai path atau jalur p2. Pada output SPSS hipotesis regresi (3) nilai unstandardized beta untuk Komunikasi Pemasaran (X) 0,705 dan Kepuasan Pelanggan (Z) 0,321 semuanya signifikan. Nilai unstandardized beta (X) 0,705 merupakan nilai jalur path p1 dan nilai unstandardized beta Kepuasan Pelanggan (Z) 0,321 merupakan nilai jalur path p3. Besarnya nilai e1 $=\sqrt{(1-0,586)}=0.643$ dan besarnya nilai e $2=\sqrt{(1-0,776)}=0,473$

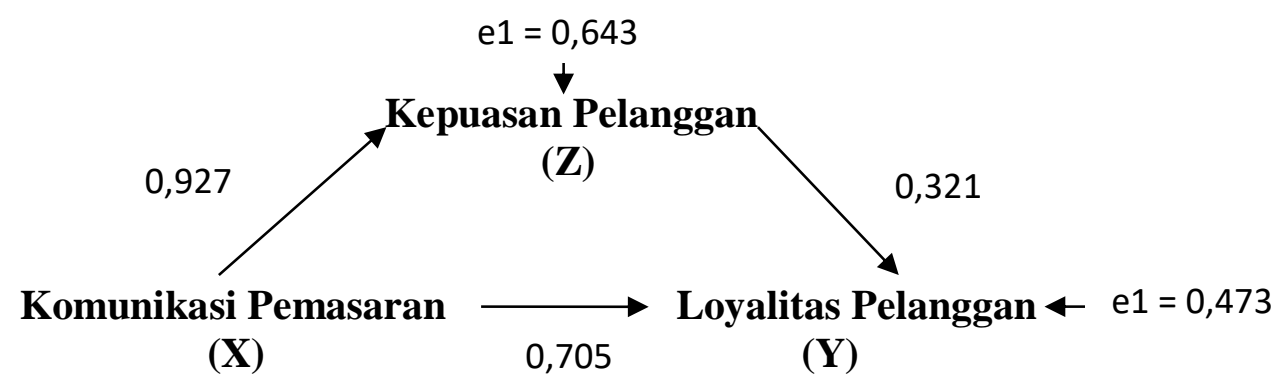

Gambar 3. Hasil Regresi Hipotesis 3

Hasil analisis jalur menunjukkan bahwa Komunikasi Pemasaran (X) dapat berpengaruh langsung ke Loyalitas Pelanggan (Y) dan dapat juga berpengaruh tidak langsung yaitu 
dari Komunikasi Pemasaran (X) ke (Z) Kepuasan Pelanggan (sebagai inter-vening) lalu ke Loyalitas Pelanggan (Y). Besarnya pengaruh langsung adalah 0,927 sedangkan besarnya pengaruh tidak langsung harus dihitung dengan mengalikan koefisien tidak langsungnya yaitu: $(0,927) \times(0,321)=0,297567$ atau total pengaruh Komunikasi Pemasaran $(\mathrm{X}) \mathrm{ke}(\mathrm{Y})$ Loyalitas Pelanggan $=0,705+(0,927 \times 0,321)=1,002567$

Pengaruh mediasi yang ditunjuk-kan oleh perkalian koefisien (p2xp3) signifikan atau tidak, diuji dengan sobel test sebagai berikut:

Hitung standar error dari koefisien indirect effect $\left(\mathrm{S}_{p 2 p 3}\right)$.

$$
\begin{aligned}
S p 2 p 3 & =\sqrt{p 3^{2} S p 2^{2}+p 2^{2} S p 3^{2}+S p 2^{2} S p 3^{2}} \\
S p 2 p 3 & =\sqrt{(0,321)^{2}(0,079)^{2}+(0,927)^{2}(0,072)^{2}+(0,079)^{2}(0,072)^{2}} \\
S p 2 p 3 & =\sqrt{\begin{array}{c}
(0,103041)(0,006241)+(0,859329)(0,005184) \\
+(0,006241)(0,005184)
\end{array}} \\
S p 2 p 3 & =\sqrt{0,0006431+0,004455+0,0000324} \\
S p 2 p 3 & =0,071628
\end{aligned}
$$

Berdasarkan hasil $S p 2 p 3$ ini kita dapat menghitung nilai t statistik pengaruh mediasi dengan rumus sebagai berikut:

$$
t=\frac{p 2 p 3}{S p 2 p 3}=\frac{0,297567}{0,071628}=4,154
$$

Oleh karena nilai t hitung $=4,154$ lebih besar dari t tabel dengan tingkat signifikan 0,05 yaitu sebesar 1,985 maka dapat disimpulkan bahwa koefisien mediasi 0, 297567 signifikan yang berarti ada pengaruh mediasi.

\section{Pembahasan}

Hasil pengujian menunjukkan bahwa variabel Komunikasi Pemasaran memberi pengaruh positif dan signifikan terhadap Loyalitas Pelanggan. Hal ini dapat dilihat dari nilai koefisien 1,003 dengan nilai signifikansi 0,000. Nilai signifikansi tersebut lebih kecil dari $0,05(0,000>0,05)$. Koefisien yang bernilai positif dapat diartikan bahwa semakin baik Komunikasi Pemasaran maka peluang Loyalitas Pelanggan pada PT. Cahaya Alam Sejati akan semakin meningkat. Artinya bahwa terdapat pengaruh antara variabel Komunikasi Pemasaran terhadap Loyalitas Pelanggan pada PT. Cahaya Alam Sejati.

Hasil pengujian menunjukkan bahwa variabel Komunikasi Pemasaran memberi pengaruh positif dan signifikan terhadap Kepuasan Pelanggan. Hal ini dapat dilihat dari nilai koefisien 0,927 dengan nilai signifikansi 0,000. Nilai signifikansi tersebut lebih kecil dari $0,05(0,000>0,05)$. Koefisien yang bernilai positif dapat diartikan bahwa semakin baik Komunikasi Pemasaran maka peluang Kepuasan Pelanggan pada PT. Cahaya Alam Sejati akan semakin meningkat. Artinya bahwa terdapat pengaruh antara variabel Komunikasi Pemasaran terhadap Kepuasan Pelanggan pada PT. Cahaya Alam Sejati.

Hasil pengujian juga menunjukkan bahwa variabel Kepuasan Pelanggan memediasi pengaruh Komunikasi Pemasaran terhadap Loyalitas Pelanggan pada PT. Cahaya Alam Sejati. Hal ini dapat dilihat dari nilai koefisien 0,705 dan 0,321 dengan nilai signifikansi 0,000. Nilai signifikansi tersebut lebih kecil dari $0,05(0,000>0,05)$. 
Koefisien yang bernilai positif dapat diartikan bahwa semakin baik Komunikasi Pemasaran maka peluang Kepuasan Pelanggan pada PT Cahaya Alam Sejati akan meningkat, sehingga menimbulkan Loyalitas Pelanggan yang juga semakin meningkat. Artinya bahwa terdapat pengaruh antara Kepuasan Pelanggan memediasi pengaruh Komunikasi Pemasaran terhadap Loyalitas Pelanggan pada PT. Cahaya Alam Sejati.

\section{KESIMPULAN DAN SARAN Kesimpulan}

Berdasarkan analisis data dan pembahasan yang dilakukan, maka kesimpulan yang diperolah dari penelitian ini adalah:

1. Hasil uji secara parsial (uji-t) menunjukkan bahwa variabel Komunikasi Pemasaran berpengaruh positif dan signifikan terhadap Loyalitas Pelanggan, Komunikasi Pemasaran berpengaruh positif dan signifikan terhadap Kepuasan Pelanggan, serta Komunikasi Pemasaran berpengaruh positif dan signifikan terhadap Loyalitas Pelanggan melalui Kepuasan Pelanggan sebagai variabel mediasi pada PT. Cahaya Alam Sejati.

2. Hasil uji secara simultan (uji F) menunjukkan bahwa variabel Komunikasi Pemasaran secara bersama-sama (serempak) memiliki pengaruh signifikan terhadap Loyalitas Pelanggan melalui Kepuasan Pelanggan sebagai variabel mediasi pada PT. Cahaya Alam Sejati.

3. Hasil uji sobel test (analisis jalur) menunjukkan bahwa variabel Kepuasan Pelanggan memediasi Komunikasi Pemasaran terhadap Loyalitas Pelanggan pada PT. Cahaya Alam Sejati.

\section{Saran}

Berdasarkan hasil penelitian secara keseluruhan, maka beberapa saran yang dapat diajukan adalah:

Disarankan kepada PT. Cahaya Alam sejati agar lebih meningkatkan Komunikasi Pemasaran agar tercapainya Kepuasan Pelanggan demi mempertahankan Loyalitas Pelanggan. Untuk itu, perlu juga untuk melakukan perbandingan seperti penjualan langsung (direct marketing) dan promosi penjualan (sales promotion) dengan perusahaan-perusahaan lain yang sejenis dalam menyampaikan Komunikasi Pemasaran, mencapai Kepuasan Pelanggan, dan mempertahankan Loyalitas Pelanggan agar tetap dapat menjaga kesetiaan pelanggan terhadap perusahaan. Bagi peneliti selanjutnya yang akan meneliti atau melanjutkan penelitian ini, disarankan untuk mengembangkan penelitian dengan menambahkan beberapa faktor lain yang mampu memengaruhi Loyalitas Pelanggan. Selain itu, penelitian dapat dikembangkan juga melalui metode pengumpulan data. Selain wawancara dan penyebaran kuisioner, dapat ditambahkan dengan metode survey lapangan serta mengamati kondisi sekitar dengan lebih intens agar data yang diperoleh lebih lengkap dan lebih membantu mendapatkan hasil yang lebih akurat. 


\section{DAFTAR PUSTAKA}

\section{Buku}

Ghozali, I. 2013. Aplikasi Analisis Multivariate dengan Program IBM SPSS 21. Edisi 1 Cetakan VII. Bandung: Badan Penerbit Universitas Diponegoro.

Kotler, P. \& Keller, K.L. 2009. Manajemen Pemasaran. Edisi 13 Jilid 1. Jakarta: Erlangga.

\section{Erlangga.} 2009. Manajemen Pemasaran. Edisi 13 Jilid 2. Jakarta:

Tjiptono, F. 2008. Strategi Pemasaran. Edisi 3. Yogyakarta: ANDI. . 2012. Service Manajemen: Mewujudkan Layanan Prima. Edisi 2. Yogyakarta: ANDI.

Tjiptono, F. dan Chandra, G. 2012. Manajemen Strategik. Edisi 2. Yogyakarta: ANDI.

Tjiptono, F. \& Diana, A. 2016. Pemasaran, Esensi \& Aplikasi. Edisi 1. Yogyakarta: ANDI.

\section{Jurnal}

Dimyati, M. 2015. "The Role of Customer Satisfaction In Mediating Marketing Communication Effect On Customer Loyalty Of The IM3 User Community In Jember Regency". Journal of Art, Science \& Commerce. Vol VI/No 4(1), Oktober, 75-87.

Chiguvi, Douglas dan Paul T. Guruwo. 2015. Impact of Customer Satisfaction on Customer Loyalty in the Banking Sector. International Journal of Scientific Engineering and Research (IJSER), Vol 5/No 2, 55-63.

Oluwafemi, Olaolu Joseph dan Sulaimon Olanrewaju Adebiyi. 2018. Customer Loyalty and Integrated Marketing Communications Among Subscribers of Telecomunication Firms in Lagos Metropolis, Nigeria. Journal of Competitiveness, Vol 10/No 3, 101-118.

Pristiyono. 2017. Faktor-Faktor Yang Mempengaruhi Kepuasan Nasabah Dan Dampaknya Pada Loyalitas Nasabah PT.Bri Simpang Enam Rantauprapat. Jurnal $\begin{array}{lllllll}\text { Ecobisma Vol } & 4 & \text { No. } & 1 & \text { Jan } & \text { 2017. } & \text { http://ojs.stie- }\end{array}$ labuhanbatu.ac.id/index.php/COBI/article/view/45/116

Purwanto, A.B \& Widodo, U.2016. "Model Pengembangan Komunikasi Pemasaran dan Kualitas Produk dalam Rangka Meraih Kepercayaan dan Loyalitas Konsumen (Studi Pada UKM di Kota Semarang)". Fokus Ekonomi, Vol 11/No 2, Desember, 51-70.

Tjahjaningsih, Endang. 2013. "Pengaruh Citra dan Promosi Terhadap Kepuasan Pelanggan Serta Dampaknya Terhadap Loyalitas Pelanggan (Studi pada Pelanggan Supermarket Carrefour di Semarang)". Media Ekonomi dan Manajemen, Vol 28/No 2, 13-27. 